(2) Open Access Full Text Article

ORIGINALRESEARCH

\title{
Biotemplate of albumen for synthesized iron oxide quantum dots nanoparticles (QDNPs) and investigation of antibacterial effect against pathogenic microbial strains
}

This article was published in the following Dove Press journal:

International Journal of Nanomedicine

Mohammad Hasan Moshafi ${ }^{1}$

Mehdi Ranjbar'

Ghazaleh Ilbeigi ${ }^{2}$

'Pharmaceutics Research Center, Institute of Neuropharmacology, Kerman University of Medical Sciences, Kerman, Iran;

${ }^{2}$ Neuroscience Research Center, Institute of Neuropharmacology, Kerman University of Medical Sciences, Kerman, Iran
Correspondence: Mehdi Ranjbar Pharmaceutics Research Center, Institute of Neuropharmacology, Kerman University of Medical Sciences,

P.O. Box: 76175-493, Kerman

76169-11319, Iran

Tel $+98343132524 \mid$

Fax +983431325003

Email Mehdi.Ranjbar@kmu.ac.ir
Background: Biotemplates are attractive templates for the synthesis of nanometals and inorganic compound nanostructures.

Methods: In this work, for the first time, iron oxide quantum dot nanoparticles (QDNPs) were prepared using albumen as a biotemplate. Next, the prepared nanoparticles were characterized using dynamic light scattering for determination and evaluation of the hydrodynamic diameter and zeta potential of the particles. Moreover, optical and scanning electron microscopes were applied to evaluate morphology. Spherically shaped iron oxide QDNPs were obtained with appropriate particle size and distribution. $\mathrm{Fe}\left(\mathrm{NO}_{3}\right)_{3} \cdot 9 \mathrm{H}_{2} \mathrm{O}$ and egg whites were used as the source of the Fe element and particle size control agent in the aqueous medium, respectively. Afterward, the effect of calcination temperature parameters on the crystallinity purity and size of $\mathrm{Fe}$ nanocrystals were investigated. Also, products were characterized by various detection analyses such as thermogravimetry analysis/DTA, XRD, UV-vis, Fourier transform infrared (FT-IR,) transmission electron microscopy, and SEM. In order to investigate the antibacterial effect of the synthesized Fe nanobiological samples against bacterial strains, they were dissolved in dimethyl sulfoxide and diluted using distilled water. Then, different serial dilutions of $64 \mu \mathrm{g} /$ $\mathrm{mL}, 32 \mu \mathrm{g} / \mathrm{mL}, 16 \mu \mathrm{g} / \mathrm{mL}, 8 \mu \mathrm{g} / \mathrm{mL}, 43 \mathrm{BCg} / \mathrm{mL}, 2 \mu \mathrm{g} / \mathrm{mL}, 1 \mu \mathrm{g} / \mathrm{mL}$, and $0.5 \mu \mathrm{g} / \mathrm{mL}$ of nanobiological samples were prepared and added to the Mueller-Hinton agar medium.

Results: The minimum inhibitory concentration of the synthesized iron oxide quantum dot nanobiological was determined against pathogenic microbial strains of bacteria including Escherichia coli, Pseudomonas aeruginosa, Serratia marcescens, Micrococcus luteus, Bacillus subtilis, Staphylococcus aureus, Staphylococcus epidermidis, and Klebsiella pneumonia on the culture medium plate.

Conclusion: The present nanobiological samples can be considered as a new material candidate for antibacterial drugs.

Keywords: iron oxide quantum dots, albumen, biotemplate, antibacterial effect

\section{Introduction}

Today, one of the problems threatening the environment and human health is the use of hazardous chemicals in the preparation of industrial, ${ }^{1}$ laboratory, ${ }^{2}$ and medical materials. ${ }^{3}$ The nonuse of hazardous substances for human health and the environment; the provision of uniformly high nanoparticles and with high efficiency, nonuse of equipment, special equipment, and physical conditions; and complex chemical solutions are among the other 
benefits of green synthesis methodology. ${ }^{4,5}$ Therefore, it is imperative to introduce and develop synthetic methods based on the principles of green chemistry on an industrial scale for industrial societies. ${ }^{6}$ The Fe nanoparticles because of their special magnetic properties have many applications in the medical field such as antioxidant properties, ${ }^{7,8}$ targeted drug delivery, ${ }^{9}$ cosmetics, ${ }^{10}$ hygiene products, catalysts, and biotechnology. ${ }^{11-13}$ Numerous chemical and physical methods have been reported for the synthesis of the Fe nanoparticles such as vapor transport, ${ }^{14}$ chemical vapor deposition, ${ }^{15}$ chemical bath deposition, ${ }^{16}$ sol-gel, ${ }^{17}$ spray pyrolysis, ${ }^{18}$ and solvothermal/hydrothermal methods. ${ }^{19}$ Also, Fe nanoparticles have been synthesized with various morphological properties such as nanowires, ${ }^{20}$ nanoneedles, ${ }^{21}$ nanoparticles, ${ }^{22,23}$ and nanorods. ${ }^{24} \mathrm{Egg}$ whites are biological and natural fluids that contain high levels of amino acids and proteins such as albumen and lysozyme. ${ }^{25}$ Structurally, these amino acids can play a stabilizing and controlling role in the synthesis of nanoparticles. ${ }^{26}$ In the last decade, many procedures have been reported for the preparation of metal nanoparticles such as $\mathrm{Au}, \mathrm{Ag}, \mathrm{Cu}, \mathrm{Pt}, \mathrm{Pd}$, and $\mathrm{Ru}$. In this regard, the hydrothermal method with potential advantages as a cost-effective, high purity, and controlled morphology are used for the synthesis of inorganic nanostructures such as metal nanoparticles and metal oxides. ${ }^{27,28}$ Fluorescent semiconductor nanoparticles with optical and superconductivity properties have great importance in various applications such as medicine, ${ }^{29}$ cell imaging, ${ }^{30}$ and other biomedical applications. ${ }^{31}$ According to literature, the magnetic nanoparticles such as Fe nanostructures give no or low toxicity in the MTT assay except for the uncoated nanoparticles. In the present work, using a simple hydrothermal method and egg white protein, we aimed to design and produce albumen as biotemplate, eco-friendly, cost-effective, a green organic matrix, and green method for producing iron oxide quantum dot monodispersed nanoparticles with well-controlled particle size. Recently, several studies have been conducted on the use of nanoparticles and nanostructures as antimicrobial agents. A summary of these works is presented in Table 1. The green pathway of preparation of iron oxide quantum dot nanoparticles (QDNPs) in albumen as biotemplate is depicted in Scheme 1. The synthesized samples were then characterized by various detection analyses such as thermogravimetry analysis (TGA)/DTA, XRD, UV-vis, Fourier transform infrared (FTIR), transmission electron microscopy (TEM), atomic force miscroscopy (AFM), and SEM.

\section{Experimental}

\section{Materials and physical measurements}

Preparation of Fe nanoparticles

Iron oxide QDNPs were prepared by a soft-chemistry synthesis involving a co-precipitating-assisted hydrothermal method. For this purpose, $0.50 \mathrm{~g} \mathrm{Fe}\left(\mathrm{NO}_{3}\right)_{3} \cdot 9 \mathrm{H}_{2} \mathrm{O}$ was dissolved in $25 \mathrm{~mL}$ distilled water. The mixture of $\mathrm{NO}_{3}$ and ferric ions was stirred for 60 mins with $400 \mathrm{rpm}$ under the argon gas (solution A). In the next step, different concentrations of freshly extracted albumen were dissolved in the relative ratio of deionized water to ethanol and then stirred at $400 \mathrm{rpm}$ in hot water bath for $30 \mathrm{mins}$ (solution B). Then, the obtained albumen suspension was added dropwise to the solution $\mathrm{A}$ and $\mathrm{pH}$ of the solution was maintained between 6.5 and 7.8 by adding $\mathrm{NaOH}$ and an ammonia solution dropwise. To prevent the agglomeration different values of $\mathrm{CTAB}$ as a surfactant, about

Table I Summary of researches about useful nanoparticles and nanocomposites as antimicrobial agents

\begin{tabular}{|c|c|c|c|c|}
\hline $\begin{array}{l}\text { Types ofnano- } \\
\text { composites }\end{array}$ & $\begin{array}{l}\text { Particle size } \\
(\mathrm{nm})\end{array}$ & $\begin{array}{l}\text { Synthesis } \\
\text { method }\end{array}$ & Microorganisms tested & References \\
\hline $\mathrm{ZnO} \mathrm{NPs}$ & $2.90-25.20$ & Green synthesis & $\begin{array}{l}\text { B. megaterium, Bacillus pumilus, } \\
\text { and } B \text {. cereus }\end{array}$ & 32 \\
\hline Pd@TiO2 & $200-400$ & $\begin{array}{l}\text { Photochemical } \\
\text { route }\end{array}$ & Escherchia coli & 33 \\
\hline $\mathrm{Cu}$ & $2-350$ & $\begin{array}{l}\text { Chemical } \\
\text { reduction }\end{array}$ & $\begin{array}{l}\text { Bacillus subtilis, Staphylococcus aureus, Pseudomonas aeruginosa, } \\
\text { and Candida albicans }\end{array}$ & 34 \\
\hline$\gamma-\mathrm{Fe} 2 \mathrm{O} 3$ & $60-80$ & $\begin{array}{l}\text { Matrix-mediated } \\
\text { method }\end{array}$ & Staphylococcus aureus & 35 \\
\hline Carbon dots/Ag & $1-5$ & $\begin{array}{l}\text { Hdrothermal } \\
\text { treatment }\end{array}$ & Staphylococcus aureus, Escherichia coli & 36 \\
\hline $\mathrm{SiO}_{2} /$ nano & 200 & $\begin{array}{l}\text { Tetraethyl } \\
\text { orthosilicate }\end{array}$ & Staphylococcus aureus & 37 \\
\hline
\end{tabular}




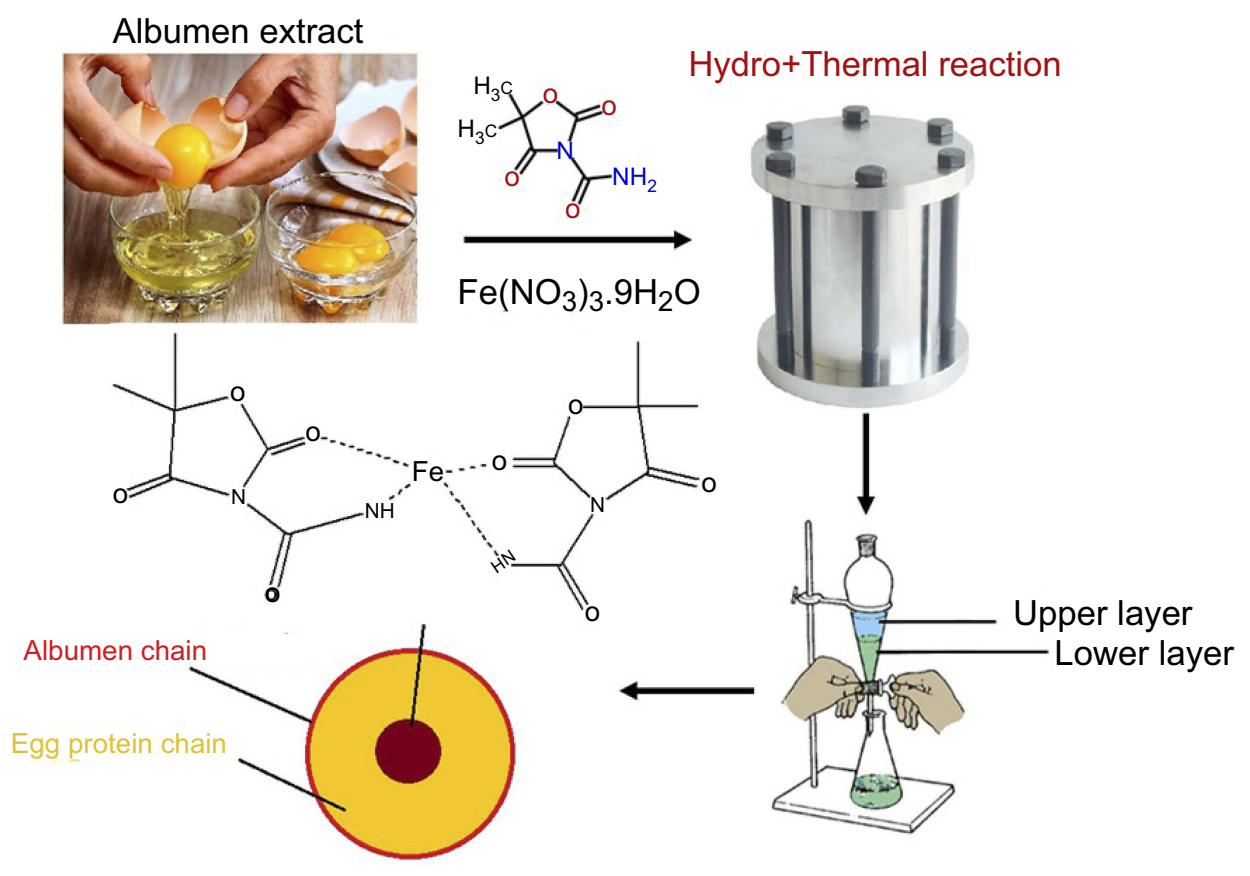

Scheme I The green pathway of preparation of iron oxide quantum dots in albumen as biotemplate.

$0.05-1.5 \mathrm{mg}$ was added to the above solutions. The suspension was transferred into a Teflon autoclave with a stainless steel shell. The autoclave was kept at 150 $220^{\circ} \mathrm{C}$ for $4-10 \mathrm{hrs}$ under various conditions according to Table 2. Eventually, the obtained black samples were washed with ethanol and acetone and dried at room temperature. The as-prepared products were analyzed by XRD, EDAX, SEM, AFM, TEM, and FTIR.

Minimum inhibitory concentration (MIC) assessment In this study, for detection of antibacterial activity of the iron oxide QDNPs, the agar dilution technique was used to measure qualitatively the in vitro activity of an antimicrobial agent against the test bacteria. In this method, graded amounts of antibiotics were incorporated in agar plates and inoculated in spots with the organisms. For this purpose, 10 small tubes were filled with $2 \mathrm{cc}$ of the Muller-Hinton broth and then 10 large tubes $(25 \mathrm{cc})$ were filled with $18 \mathrm{cc}$ of the Muller-Hinton agar and transferred to the autoclave. In the next step, the first tube was added to $2 \mathrm{~mL}$ of the stock solution and after mixing, $2 \mathrm{cc}$ of the first tube was added to the second tube. This process was continued until $2 \mathrm{cc}$ of the final tube was poured out and 8 consecutive dilutions were prepared from the specimen and concentrations of $640 \mu \mathrm{g} / \mathrm{mL}, 320 \mu \mathrm{g} / \mathrm{mL}, 160 \mu \mathrm{g} / \mathrm{mL}, 80 \mu \mathrm{g} / \mathrm{mL}, 40$ $\mu \mathrm{g} / \mathrm{mL}, 20 \mu \mathrm{g} / \mathrm{mL}, 10 \mu \mathrm{g} / \mathrm{mL}$, and $5 \mu \mathrm{g} / \mathrm{mL}$ were obtained. Each of these dilutions was then added to $18 \mathrm{cc}$ of solid culture medium and the final concentrations were achieved as $64 \mu \mathrm{g} / \mathrm{mL}, 32 \mu \mathrm{g} / \mathrm{mL}, 16 \mu \mathrm{g} / \mathrm{mL}, 8 \mu \mathrm{g} / \mathrm{mL}, 4 \mu \mathrm{g} / \mathrm{mL}$, $2 \mu \mathrm{g} / \mathrm{mL}, 1 \mu \mathrm{g} / \mathrm{mL}$, and $0.5 \mu \mathrm{g} / \mathrm{mL}$.

\section{Results and discussion \\ Characterization of iron oxide QDNPs}

The XRD analyses at low angles can be used to identify the crystalline phases present in a material and then obtain chemical composition information in order to prove the success of the exchange reaction. The peaks appeared at $2 \theta=45.56^{\circ}$ and $65.54^{\circ}$ can be indexed to the characteristic diffraction peaks of (110) and (200) planes of cubic iron oxide quantum dots (JCPDS No. 87-0721) and space group number: 229. In order to interpret X-ray pattern, the relationship between the

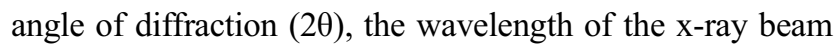
$(\lambda)$, and the distance between each set of atomic planes of the crystal lattice (d), Deby-Sherrer equation (Eq. 1) can be employed. This equation gives the mean diameter of the crystallites with the help of the following formula:

$$
\mathrm{D}=\mathrm{k} \lambda / \beta \cos (\theta)
$$

where $\mathrm{D}$ is mean crystallites size, $\lambda$ is $\mathrm{X}$-ray wavelength (1.54056 $\AA$ ), $\beta$ is broadening of the line measured at half its maximum intensity (in radius), $\theta$ is diffraction angle from Bragg planes, and $\mathrm{k}$ is shape factor (0.9). Figure 1A shows the XRD pattern of the products before annealing 

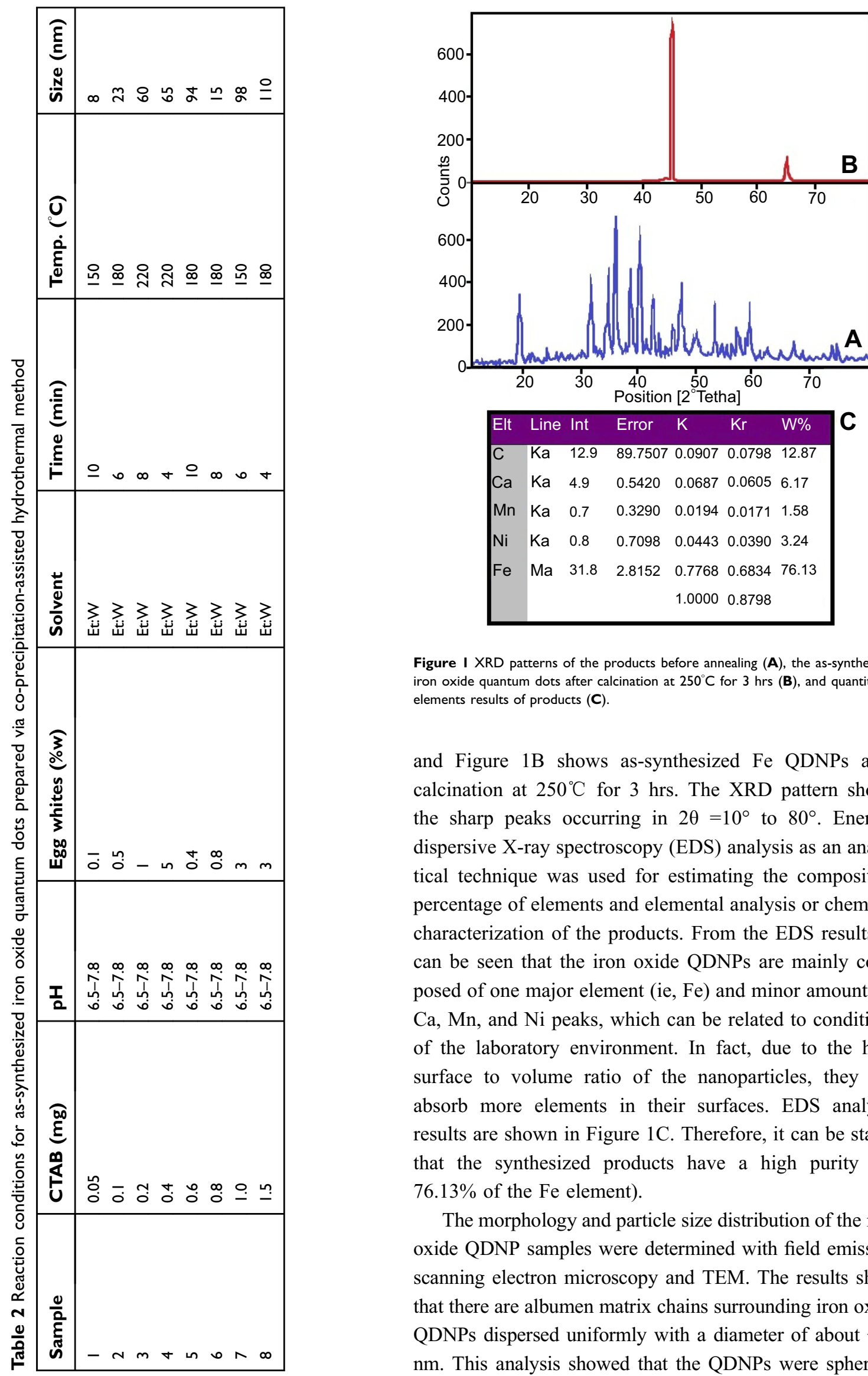

Figure I XRD patterns of the products before annealing $(\mathbf{A})$, the as-synthesized iron oxide quantum dots after calcination at $250^{\circ} \mathrm{C}$ for $3 \mathrm{hrs}(\mathbf{B})$, and quantitative elements results of products $(\mathbf{C})$.

and Figure 1B shows as-synthesized Fe QDNPs after calcination at $250^{\circ} \mathrm{C}$ for $3 \mathrm{hrs}$. The XRD pattern shows the sharp peaks occurring in $2 \theta=10^{\circ}$ to $80^{\circ}$. Energydispersive X-ray spectroscopy (EDS) analysis as an analytical technique was used for estimating the composition percentage of elements and elemental analysis or chemical characterization of the products. From the EDS results, it can be seen that the iron oxide QDNPs are mainly composed of one major element (ie, $\mathrm{Fe}$ ) and minor amounts of $\mathrm{Ca}, \mathrm{Mn}$, and Ni peaks, which can be related to conditions of the laboratory environment. In fact, due to the high surface to volume ratio of the nanoparticles, they can absorb more elements in their surfaces. EDS analysis results are shown in Figure 1C. Therefore, it can be stated that the synthesized products have a high purity (ie, $76.13 \%$ of the Fe element).

The morphology and particle size distribution of the iron oxide QDNP samples were determined with field emission scanning electron microscopy and TEM. The results show that there are albumen matrix chains surrounding iron oxide QDNPs dispersed uniformly with a diameter of about $<80$ $\mathrm{nm}$. This analysis showed that the QDNPs were spherical 
and homogenous and did not produce aggregates. The particle sizes observed in the TEM images are consistent with the sizes obtained with dynamic light scattering (DLS). The results showed that using albumen as a biotemplate during the synthesis leads to products with less agglomeration and high uniformity. Figure 2A and B present the spherical morphology of the iron oxide QDNPs from SEM and TEM images, respectively.

DLS, as a nondestructive analysis, is utilized for measuring the hydrodynamic size of molecules and submicron particles. Therefore, the light diffusion method is one of the methods for determining the size and distribution of particle size in QDNP structures. DLS results of iron oxide QDNPs showed that the biotemplate of albumen and synthesis methods could have a positive effect on the distribution particle size of the products. DLS of the iron oxide QDNPs is illustrated in Figure 2C.

The unique properties of Fe QDNPs such as topography and interactions are because of their morphological
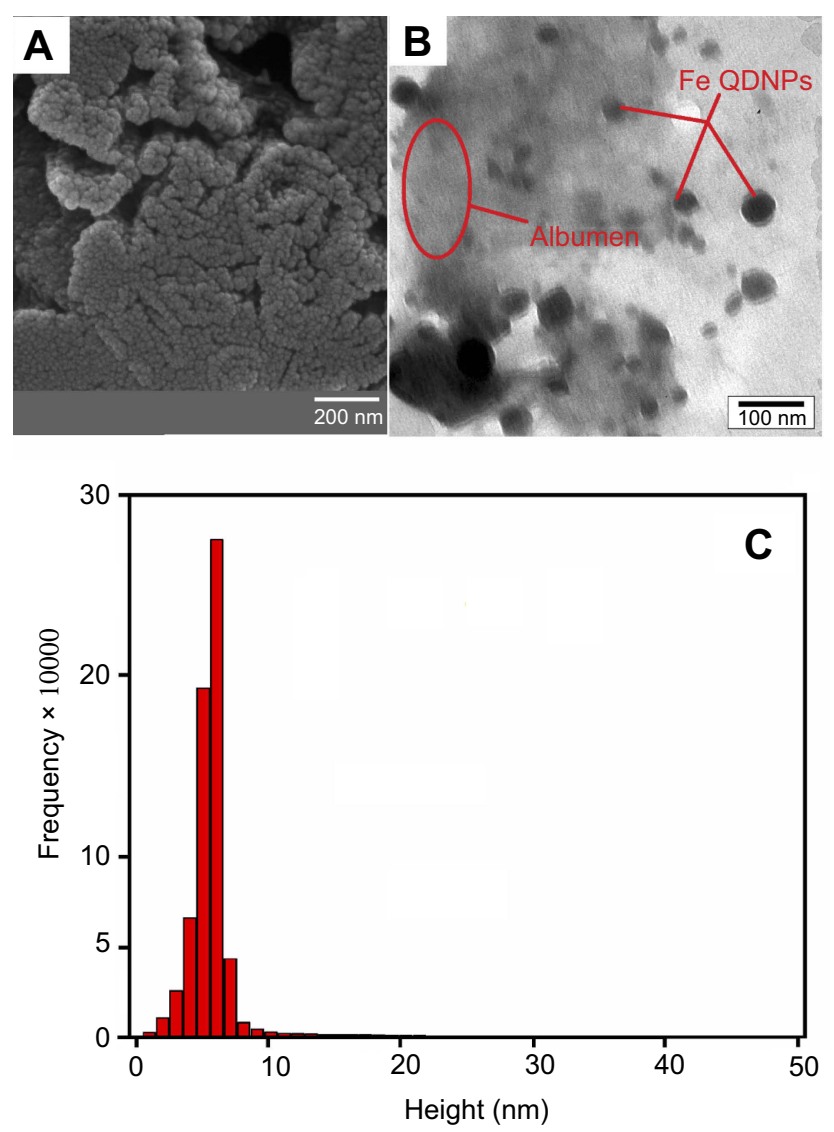

Figure 2 The SEM image (A), TEM image (B) dynamic light scattering as-synthesized iron oxide quantum dots prepared via co-precipitation-assisted hydrothermal method $S_{1}(\mathbf{C})$.

Abbreviations: SEM, scanning electron microscope; TEM, transmission electron microscopy and distribution particle size. AFM is a suitable technique to characterize the size and shape of QDNPs through the force between the tip and the sample that can produce a three-dimensional image of the iron oxide QDNPs surfaces. The AFM image (topography) in Figure 3A shows the formation of layers of three-dimensional spherical iron oxide QDNPs. The AFM image demonstrates the suitable distribution and in the surface topography of nanoparticle size at a cross-section of the sample. Brunauer-EmmettTeller was used for measuring the specific surface area and porosity of the nanomaterials. The $\mathrm{N}_{2}$ adsorption-desorption isotherms and pore size distribution of the iron oxide QDNPs are shown in Figure 3B. The average pore size of products is estimated from the pore volume. Assuming a cylindrical pore geometry (type-A hysteresis), the average pore radius $\left(r_{p}\right)$ can be expressed as Eq. 2:

$$
\mathrm{r}_{\mathrm{p}}=2 \mathrm{~V}_{\text {liq }} / \mathrm{S}
$$

Total pore volume in iron oxide QDNPs is derived from the amount of vapor adsorbed at a relative temperature close to unity (assuming pores are filled with liquid adsorbate), which can be calculated as Eq. 3:

$$
\mathrm{V}_{\text {liq }}=\mathrm{P}_{\mathrm{a}} \mathrm{V}_{\mathrm{ads}} \mathrm{V}_{\mathrm{m}} / \mathrm{R} \mathrm{T}
$$

where $\mathrm{V}_{\mathrm{ads}}, \mathrm{V}_{\text {liq }}$, and $\mathrm{V}_{\mathrm{m}}$ indicate, respectively, the volume of gas adsorbed, the volume of liquid $\mathrm{N}_{2}$ in pores, and

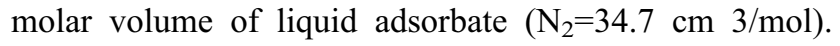
Also, $\mathrm{P}_{\mathrm{a}}$ and $\mathrm{T}$ show ambient pressure and ambient temperature, respectively. The results showed that the characterized heats of adsorption are less than the adsorbate heat of liquefaction. Moreover, it is seen that adsorption proceeds as the adsorbate interaction with an adsorbed layer exceeds the interaction with the adsorbent surface. According to calculations, adsorption cross-section area, standard volume, and dead volume were estimated to be $0.162 \mathrm{~nm}^{2}, 9.779 \mathrm{~cm}^{3}$, and $15.972 \mathrm{~cm}^{3}$, respectively.

TGA can be used to study the mass change of samples under a programmed condition. The TG curves of the iron oxide QDNPs (Figure 3C) demonstrate a single stage of weight loss or decomposition. The weight loss occurred in the temperature range of $120-145^{\circ} \mathrm{C}$ is related to the decomposition of albumen chain and egg proteins chain from around of nanoparticles. After $145^{\circ} \mathrm{C}$, iron oxide QDNPs reach relative temperature stability.

QDNPs as semiconductor nanocrystals exhibit unique optical properties because of their combined material band gap energy and quantum well phenomena, discussed in the previous section. One of the important properties of the 

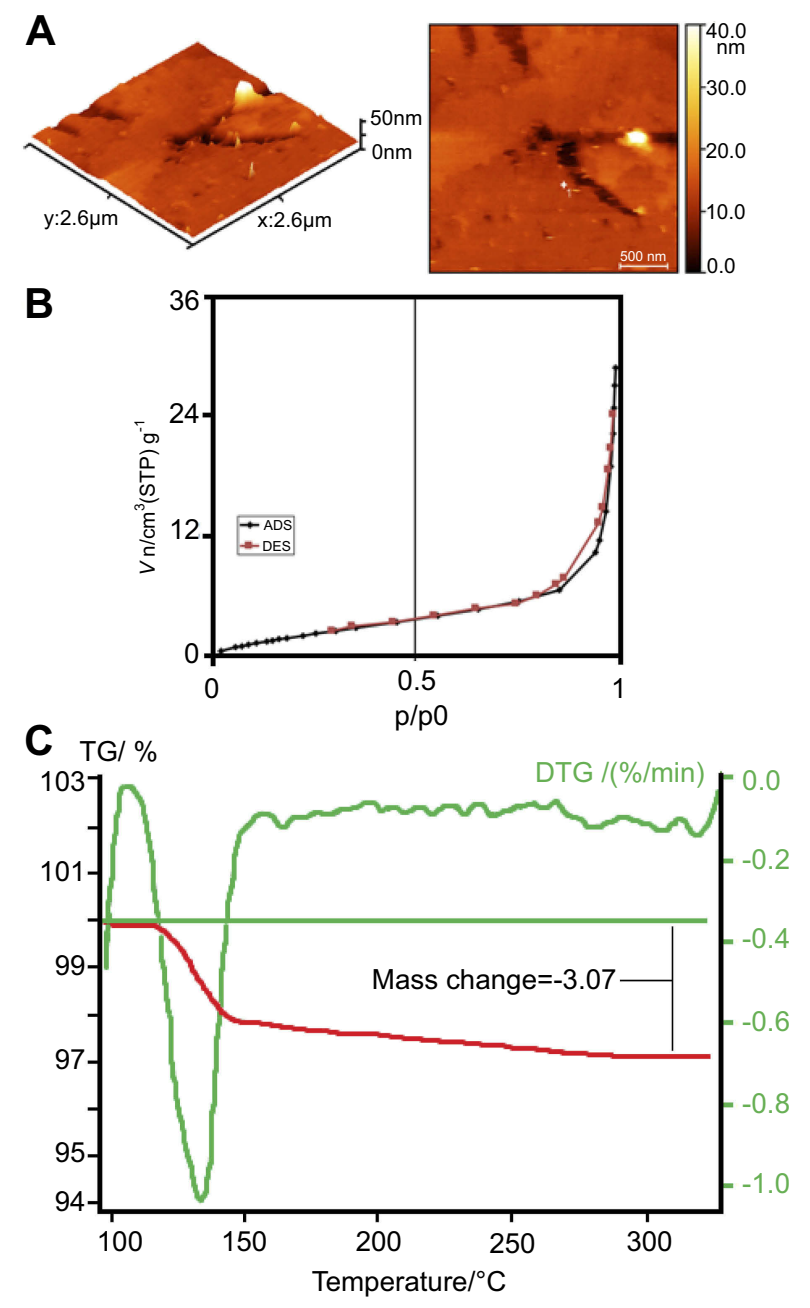

Figure 3 AFM images of the synthesized iron oxide quantum dots (A), the $N_{2}$ adsorption/desorption (ADS/DES) isotherm at room temperature (B), and TGA profile obtained for iron oxide quantum dots (C).

Abbreviations: AFM, atomic force miscroscopy; TGA, thermogravimetry analysis; DTG, derivative thermogravimetry.

QDNPs is their energy gap and the estimated absorption rate between valance and conduction bands. When the electrons are excited by an energetic source, their energy is equal to the energy band gap, which is an optical absorption edge in the absorption spectra. The QDNPs band gap can be estimated as Eq. 4.

$$
\mathrm{E}_{\mathrm{g}}=\mathrm{hc} / \lambda
$$

Figure 4A shows the UV-Vis absorption spectra of the iron oxide QDNPs in the room temperature and optical properties of samples with visualizer 160818. The Fe QDNPs band gaps of the nanostructures are higher than the bulk iron oxide, which can be attributed to the quantum confinement effects. This effect shifted the absorption spectra to the blue region in samples such that the sizes of $S_{1}$ and
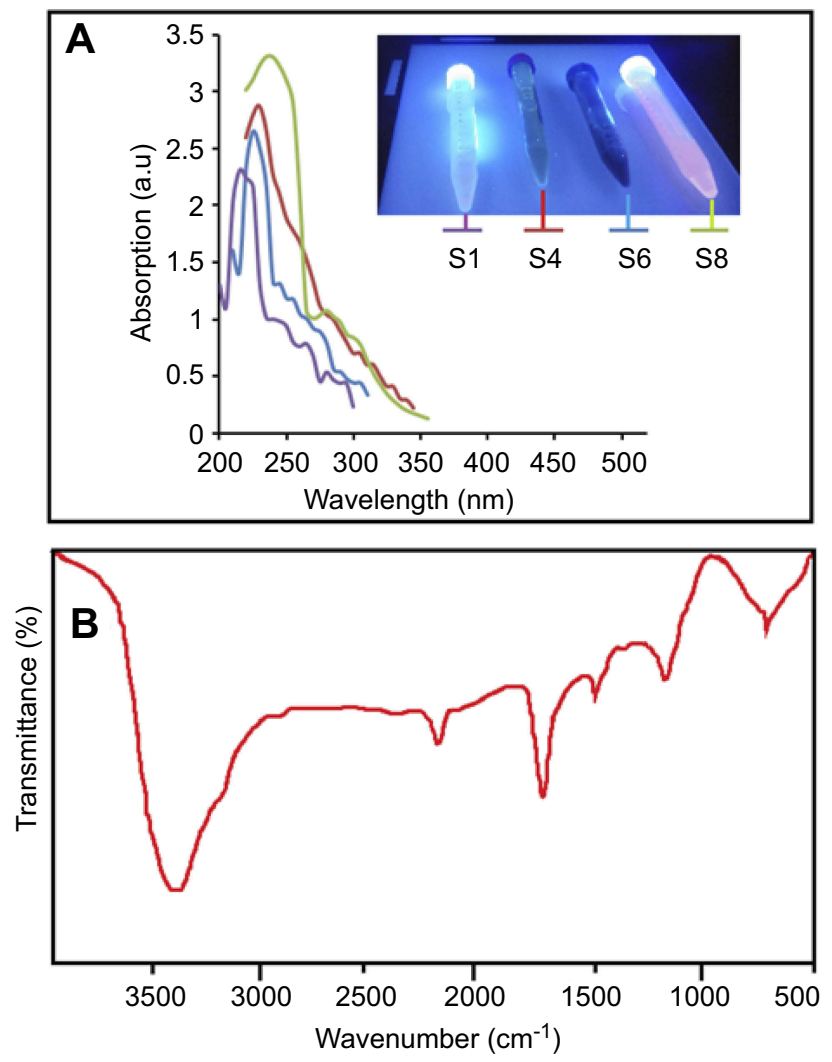

Figure 4 The ultraviolet-visible spectrum of SI, S4, S6, and S8 (A) and the Fourier transform infrared spectrum of the iron oxide quantum dots $\mathrm{SI}(\mathbf{B})$.

$\mathrm{S}_{6}$ are $215 \mathrm{~nm}$ and $225 \mathrm{~nm}$, respectively; these data are in good agreement with the particles size of the iron oxide QDNPs. Also, in samples $\mathrm{S}_{4}$ and $\mathrm{S}_{8}$ with $65 \mathrm{~nm}$ and 110 $\mathrm{nm}$ particle sizes, the UV-vis absorption spectra show 230 $\mathrm{nm}$ and $240 \mathrm{~nm}$ values, which can be related to redshift in products. FTIR spectroscopy is one of the most important techniques used to identify functional groups. The absoption bands at $3443 \mathrm{~cm}^{-1}$ (O-H stretching), $2323 \mathrm{~cm}^{-1}(\mathrm{C}-$ O bending), $1621 \mathrm{~cm}^{-1}$ (N-H stretching), $1033 \mathrm{~cm}^{-1}$ (C-H stretching), and $612 \mathrm{~cm}^{-1}$ related to vibrations of $\mathrm{Fe}-\mathrm{O}$ bonds in iron oxide QDNPs are shown in Figure 4B.

$\mathrm{X}$-ray photoelectron spectroscopy (XPS) as a nondestructive analysis can provide fundamental information about elemental distributions, layer thicknesses, and surface structures. Moreover, this analysis provides information about nanoparticles with sizes below $20 \mathrm{~nm}$, which may not be readily analyzed by other methods. XPS spectrum of iron oxide QDNPs is presented in Figure 5A The photoelectron peaks at ranges about $714.11 \mathrm{eV}, 534.12 \mathrm{eV}$, $310.87 \mathrm{eV}$, and $208.89 \mathrm{eV}$ are related to the binding energies of iron, oxygen, nitrogen, and carbon, respectively. The narrow scan of iron oxide QDNPs 2p-electrons is 

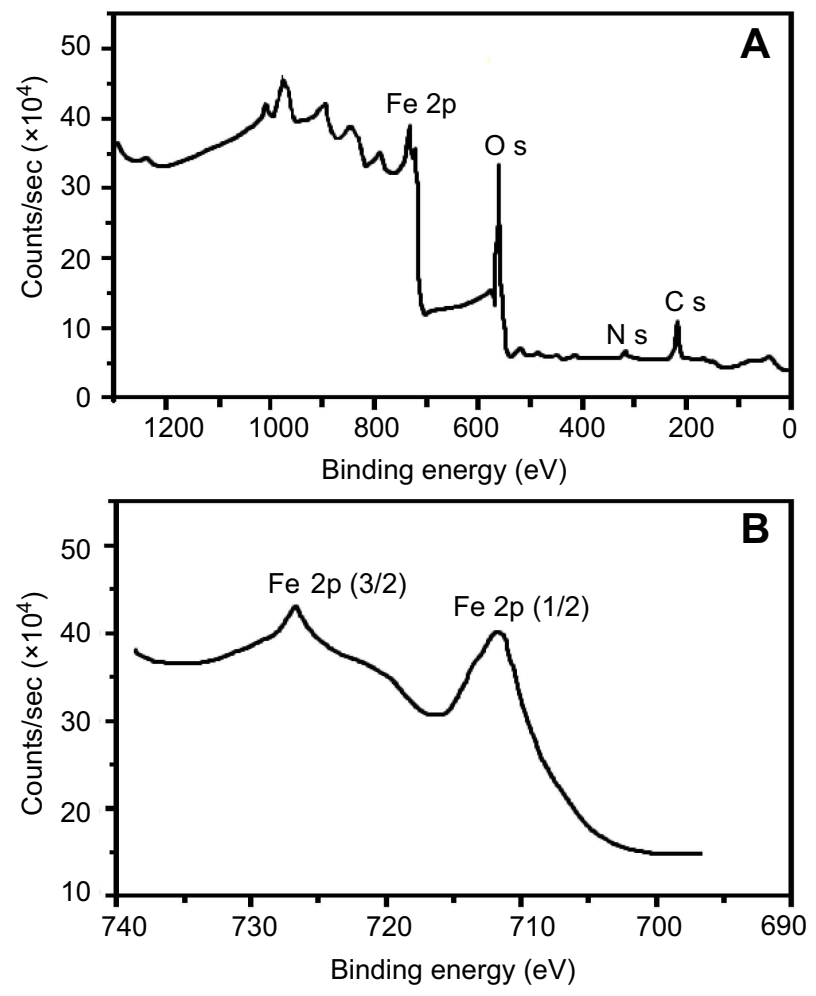

Figure 5 X-ray photoelectron spectroscopy spectrum of iron oxide quantum dot nanoparticles (QDNPs) (A) and the narrow scan of iron oxide QDNPs 2p-electrons (B).

shown in Figure 5B. The XPS spectrum of iron oxide QDNPs 2p-electrons shows two binding energies, which are related to $\mathrm{Fe} 2 \mathrm{p}(3 / 2)$ and $\mathrm{Fe} 2 \mathrm{p}(1 / 2)$ at about 726.82 and $712.9 \mathrm{eV}$, respectively. Therefore, the obtained results demonstrate that the iron oxides are present on the surface of the as-synthesized nanoparticles. The presence of carbon elements indicates that the albumen as a biotemplate and biomolecules acted as a capping agent for the synthesized iron oxide QDNPs structures.

Antibacterial activity of iron oxide QDNPs against 4 Gram-negative and 4 Gram-positive bacteria using agar well diffusion with nanocomposites prepared under different conditions as $64 \mu \mathrm{g} / \mathrm{mL}, 32 \mu \mathrm{g} / \mathrm{mL}, 16 \mu \mathrm{g} / \mathrm{mL}, 8 \mu \mathrm{g} / \mathrm{mL}, 4$ $\mu \mathrm{g} / \mathrm{mL}, 2 \mu \mathrm{g} / \mathrm{mL}, 1 \mu \mathrm{g} / \mathrm{mL}$, and $0.5 \mu \mathrm{g} / \mathrm{mL}$ in solid culture media from 1 to 8, respectively, are shown in Figure 6. The MIC of the iron oxide QDNPs samples for Gram-positive and Gram-negative bacterial strains is illustrated in Table 3. The results showed that the Fe QDNP samples had the maximum sensitivity and antimicrobial properties against all Gram-negative microbial strains, except E. coli PTCC 1330 that showed growth in about $0.5 \mu \mathrm{g} / \mathrm{ml}$. Also, for Gram-positive strains, it can be stated there is some growth within $0.5 \mu \mathrm{g} / \mathrm{mL}$ to $2 \mu \mathrm{g} / \mathrm{mL}$ and $0.5 \mu \mathrm{g} / \mathrm{mL}$ for M. luteus PTCC.1110, and S. aureus PTCC.1112, respectively.

Iron oxide QDNPs applied the antibacterial effect in two viewpoints. First, these quantum dots can reduce ATP synthase activities by changing the membrane potential, which leads to a decrease in the metabolism process. Second, collapsing biological mechanism of bacteria through refused the subunit of the ribosome binding. At the same time, they proved to be less toxic to mammal cells. ${ }^{38}$ Shrinking QD structures and increasing the surface-to-volume ratio resulted in an increase in surface activity and hence provided an improved contact with the bacteria. These two important reasons greatly enhanced the antimicrobial activity of the quantum dots. Iron oxide QDNPs disturbed the normal functioning of bacterial proteins of the cell wall and caused cell death. ${ }^{39}$ Iron oxide

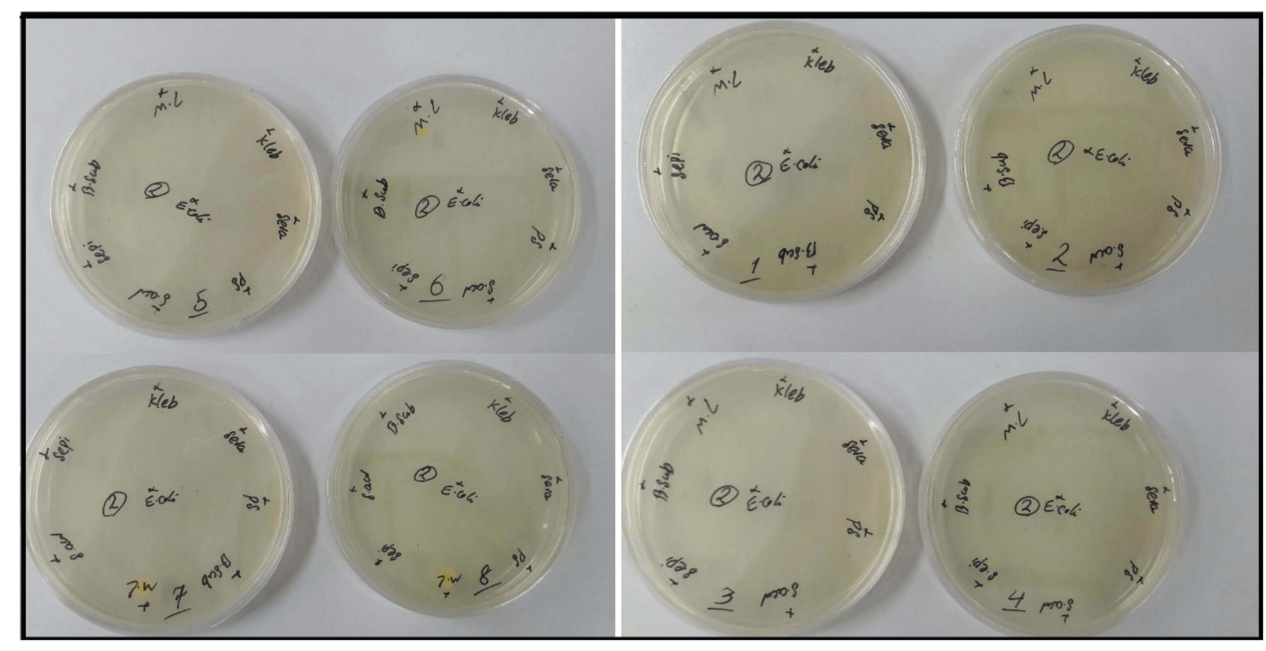

Figure 6 Antibacterial activity of the iron oxide quantum dots against 4 Gram-negative and 4 Gram-positive bacteria. Different serial dilutions as 64 (plate I), 32 (plate 2), 16 (plate 3), 8 (plate 4), 4 (plate 5), 2 (plate 6), I (plate 7) , and 0.5 (plate 8) $\mu \mathrm{g} / \mathrm{mL}$ in the Muelle-Hinton agar medium. 


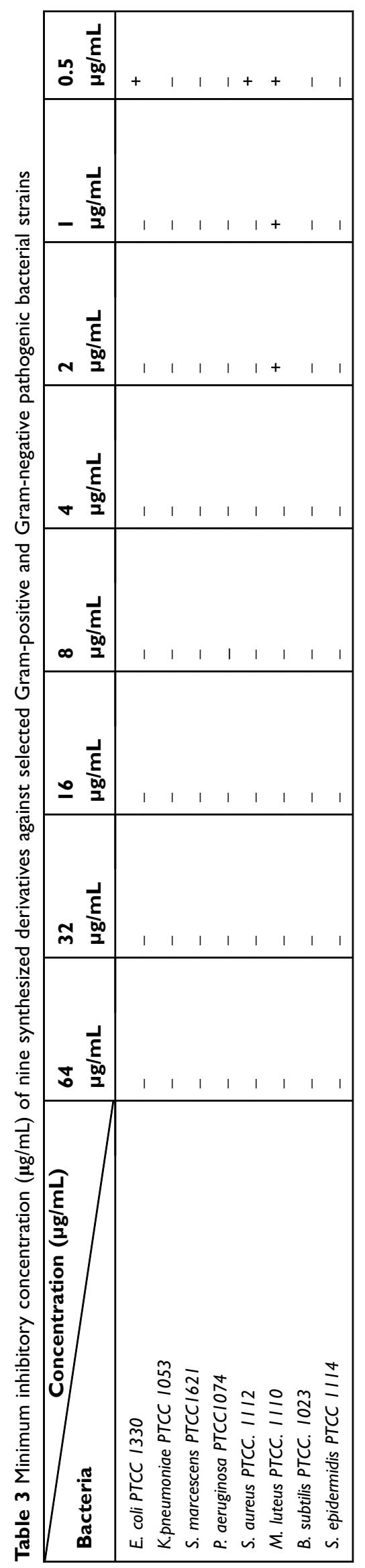

QDNPs, because of their high surface-to-volume ratio, can easily react with phosphorus or sulfur in DNA molecules at cell wall bacteria. The iron oxide QDNPs bounded with thiol groups of enzymes through the release of oxygen species and disrupted their respiratory chains. Therefore, damage occurred in the cell structures and finally led to cell death mechanism. ${ }^{40,41}$

\section{In vivo study}

To investigate optical properties of iron oxide QDNPs, we dissolved $0.005 \mathrm{mg} / \mathrm{mL}$ QDs at 1:2 ratio of threetimes distilled water to ethanol and injected them to the rat tail (Balb/c male). Next, anesthesia was injected with a 1:2 ratio of ketamine/xylazine immediately. Male Balb/c weighing 150-200 $\mathrm{g}$ was fed with standard diet and kept under 12:12 hr light/dark cycles, at $20 \square$ and relative humidity of $25-30 \%$. This study received ethical approval (96000752) from the local ethical committee of the Kerman University of Medical Sciences. First, no optical properties were observed, but after 3 mins, the optical properties of iron oxide QDNPs can appear in images. Injection stage and in vivo image of mice 3 mins after of injection are illustrated in Figure 7A and $\mathrm{B}$, respectively.

\section{Conclusions}

The shape of nanoparticles has a strong effect on the antibacterial properties. Our results, for the first time, show the preparation of iron oxide QDNPs synthesized with albumen as biotemplate. Nonuse of harmful chemicals in the preparation of the iron oxide QDNPs with suitable extensibility in albumen and unique optical properties are very important and useful in different applications. The iron oxide QDNPs have significant antibacterial activity against Gram-positive and Gram-negative bacteria. Products in this study were characterized by AFM, XRD, SEM, TEM, FTIR, and UV-vis. To gain further insight, it is suggested conducting some in vivo studies for confirmation of antibacterial results and in vitro observations.

\section{Research Highlights}

(a) For the first time, iron oxide quantum dots nanoparticles synthesized with an albumen as biotemplate.

(b) Iron oxide quantum dots synthesized with perfect distribution and uniform particle size about 5-9 $\mathrm{nm}$. 

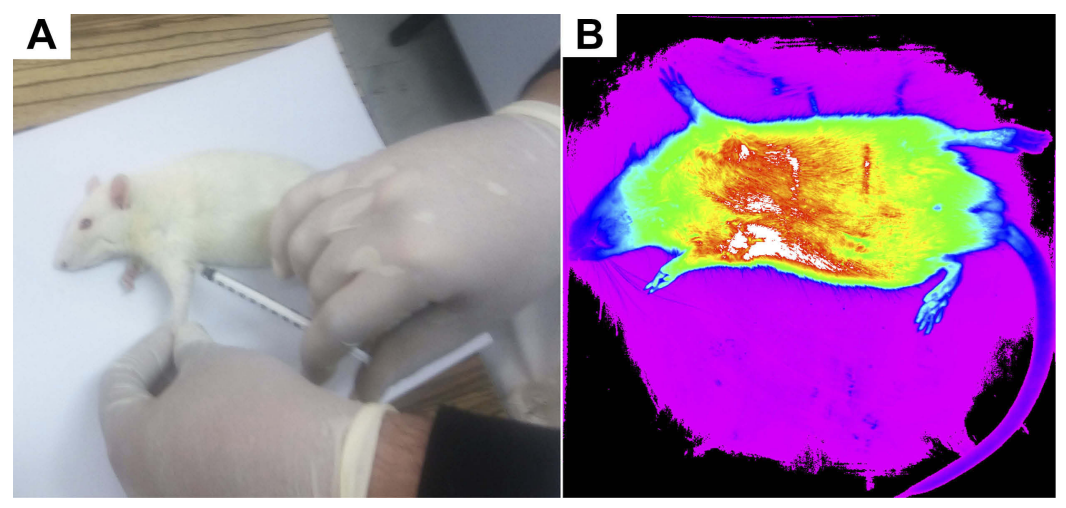

Figure 7 Injection stage (A) and in vivo image of mice 3 mins after of injection (B).

(c) The albumen acts as a biomolecules template, green reductance, and capping agent for the synthesized iron oxide quantum dots structures.

(d) Iron oxide quantum dots show high sensitivity antibacterial activity especially against Gram-positive and Gram-negative bacteria.

\section{Compliance with Ethics Requirements}

This article does not contain any studies with human subjects. The mice (BALB/c male purchased from Animal care center) were feeded and raised according to the Institutional Animal Care and Use Committee (IACUC) protocol

\section{Acknowledgments}

The authors thank the Institute of Neuropharmacology, Kerman University of Medical Sciences, also the Laboratory of Nanostructures and Nanodrugs Materials, Kerman, Iran for the use of laboratory equipment such as nano-fabrication devices as well as Ultraviolet (UV) imaging spectroscopy.

\section{Disclosure}

The authors report no conflicts of interest in this work.

\section{References}

1. Marambio-Jones C, Hoek EM. A review of the antibacterial effects of silver nanomaterials and potential implications for human health and the environment. J Nanopart Res. 2010;12(5):1531-1551. doi:10.1007/ s11051-010-9900-y

2. Hemmati S, Rashtiani A, Zangeneh MM, Mohammadi P, Zangeneh A, Veisi $H$. Green synthesis and characterization of silver nanoparticles using Fritillaria flower extract and their antibacterial activity against some human pathogens. Polyhedron. 2019;158:8-14. doi:10.1016/j.poly.2018.10.049
3. Paredes-Belmar G, Bronfman A, Marianov V, Latorre-Núñez G. Hazardous materials collection with multiple-product loading. $J$ Clean Prod. 2017;141:909-919. doi:10.1016/j.jclepro.2016.09.163

4. Scheepers PTJ, van Brederode NE, Bos PMJ, et al. Human biological monitoring for exposure assessment in response to an incident involving hazardous materials. Toxicol Lett. 2014;231(3):295-305. doi:10.1016/j.toxlet.2014.03.002

5. Burgess JL, Keifer MC, Barnhart S, Richardson M, Robertson WO. Hazardous materials exposure information service: development, analysis, and medical implications. Ann Emerg Med. 1997;29(2):248-254.

6. Ahmed S, Ahmad M, Swami BL, Ikram S. A review on plants extract mediated synthesis of silver nanoparticles for antimicrobial applications: a green expertise. $J$ adv res. 2016;7(1):17-28. doi:10.1016/j. jare.2015.02.007

7. Ho D, Sun X, Sun S. Monodisperse magnetic nanoparticles for theranostic applications. Acc Chem Res. 2011;44(10):875-882. doi:10.1021/ar200090c

8. Gao J, Gu H, Xu B. Multifunctional magnetic nanoparticles: design, synthesis, and biomedical applications. Acc Chem Res. 2009;42 (8):1097-1107. doi:10.1021/ar9000026

9. Vivero-Escoto JL, Slowing II, Trewyn BG, Lin VS-Y. Mesoporous silica nanoparticles for intracellular controlled drug delivery. Small. 2010;6(18):1952-1967. doi:10.1002/smll.200901789

10. Peng S, Wang C, Xie J, Sun S. Synthesis and stabilization of monodisperse Fe nanoparticles. J Am Chem Soc. 2006;128(33):1067610677. doi:10.1021/ja063969h

11. Kratošová G, Holišová V, Konvičková Z, et al. From biotechnology principles to functional and low-cost metallic bionanocatalysts. Biotechnol Adv. 2019;37(1):154-176. doi:10.1016/j. biotechadv.2018.11.012

12. Mehta RV. Synthesis of magnetic nanoparticles and their dispersions with special reference to applications in biomedicine and biotechnology. Mater Sci Eng C. 2017;79:901-916. doi:10.1016/j.msec.2017.05.135

13. Moldes-Diz Y, Eibes G, Vázquez-Vázquez C, et al. A novel enzyme catalysis reactor based on superparamagnetic nanoparticles for biotechnological applications. J Environ Chem Eng. 2018;6(5):59505960. doi:10.1016/j.jece.2018.09.014

14. Hussain R, Khan MQ, Khan AA. Tetrahydrofuran vapour sensing by electrically conductive silver nanoparticle doped Poly-1-napthylaminetitanium(IV)sulphosalicylophosphate ion exchange nanocomposite. $J$ Ind Eng Chem. 2019;70:186-195. doi:10.1016/j.jiec.2018.10.015

15. Esteves LM, Oliveira HA, Passos FB. Carbon nanotubes as catalyst support in chemical vapor deposition reaction: a review. J Ind Eng Chem. 2018;65:1-12. doi:10.1016/j.jiec.2018.04.012

16. Zhao F, Huang W, Zhou D. Chemical bath deposition synthesis of nickel cobalt oxides/sulfides for high-performance supercapacitors electrode materials. J Alloys Compd. 2018;755:15-23. doi:10.1016/ j.jallcom.2018.04.304 
17. Deng Y-H, Wang -C-C, Hu J-H, Yang W-L, Fu S-K. Investigation of formation of silica-coated magnetite nanoparticles via sol-gel approach. Colloids Surf A Physicochem Eng Asp. 2005;262(13):87-93. doi:10.1016/j.colsurfa.2005.04.009

18. Channei D, Inceesungvorn B, Wetchakun N, et al. Photocatalytic activity under visible light of Fe-doped $\mathrm{CeO} 2$ nanoparticles synthesized by flame spray pyrolysis. Ceram Int. 2013;39(3):3129-3134. doi:10.1016/j.ceramint.2012.09.093

19. Pang YL, Lim S, Ong HC, Chong WT. Research progress on iron oxide-based magnetic materials: synthesis techniques and photocatalytic applications. Ceram Int. 2016;42(1):9-34. doi:10.1016/j. ceramint.2015.08.144

20. Liang C, Meng GW, Zhang LD, Wu YC, Cui Z. Large-scale synthesis of $\beta$-SiC nanowires by using mesoporous silica embedded with $\mathrm{Fe}$ nanoparticles. Chem Phys Lett. 2000;329(3-4):323-328. doi:10.1016/ S0009-2614(00)01023-X

21. Mendoza-Reséndez R, Luna C, Barriga-Castro ED, Bonville P, Serna CJ. Control of crystallite orientation and size in Fe and FeCo nanoneedles. Nanotechnology. 2012;23(22):225601. doi:10.1088/09574484/23/22/225601

22. Fang J, Kumbhar A, Zhou WL, Stokes KL. Nanoneedles of maghemite iron oxide prepared from a wet chemical route. Mater Res Bull. 2003;38(3):461-467. doi:10.1016/S0025-5408(02)01066-8

23. Mofradnia SR, Tavakoli Z, Yazdian F, Rashedi H, Rasekh B. Fe/ starch nanoparticle - Pseudomonas aeruginosa: bio-physiochemical and MD studies. Int J Biol Macromol. 2018;117:51-61. doi:10.1016/ j.ijbiomac.2018.04.191

24. Nadagouda MN, Varma RS. Microwave-assisted shape-controlled bulk synthesis of $\mathrm{Ag}$ and $\mathrm{Fe}$ nanorods in poly (ethylene glycol) solutions. Cryst Growth Des. 2007;8(1):291-295. doi:10.1021/ $\operatorname{cg} 070473 \mathrm{i}$

25. Gabal MA. Magnetic properties of NiCuZn ferrite nanoparticles synthesized using egg-white. Mater Res Bull. 2010;45(5):589-593. doi:10.1016/j.materresbull.2010.01.021

26. Lai BH, Yeh -C-C, Chen DH. Surface modification of iron oxide nanoparticles with polyarginine as a highly positively charged magnetic nano-adsorbent for fast and effective recovery of acid proteins. Process Biochem. 2012;47(5):799-805. doi:10.1016/j. procbio.2012.02.010

27. Chen S, Yuan R, Chai Y, Hu F. Electrochemical sensing of hydrogen peroxide using metal nanoparticles: a review. Mikrochim Acta. 2013;180(1-2):15-32. doi:10.1007/s00604-012-0904-4

28. Hua M, Zhang S, Pan B, Zhang W, Lv L, Zhang Q. Heavy metal removal from water/wastewater by nanosized metal oxides: a review. $J$ Hazard Mater. 2012;211-212:317-331. doi:10.1016/j. jhazmat.2011.10.016
29. Gao G, Jiang Y-W, Sun W, Wu F-G. Fluorescent quantum dots for microbial imaging. Chinese Chem Lett. 2018;29(10):1475-1485. doi:10.1016/j.cclet.2018.07.004

30. Medintz IL, Uyeda HT, Goldman ER, Mattoussi H. Quantum dot bioconjugates for imaging, labelling and sensing. Nat Mater. 2005;4 (6):435. doi:10.1038/nmat 1390

31. Zhou J, Yang Y, Zhang C-Y. Toward biocompatible semiconductor quantum dots: from biosynthesis and bioconjugation to biomedical application. Chem Rev. 2015;115(21):11669-11717. doi:10.1021/acs. chemrev.5b00049

32. Nagajyothi P, Sreekanth TVM, Tettey CO, Jun YI, Mook SH. Characterization, antibacterial, antioxidant, and cytotoxic activities of $\mathrm{ZnO}$ nanoparticles using coptidis rhizoma. Bioorg Med Chem Lett. 2014;24(17):4298-4303. doi:10.1016/j.bmcl.2014.07.023

33. Chen SF, Li JP, Qian K, et al. Large scale photochemical synthesis of $\mathrm{M} @ \mathrm{TiO} 2$ nanocomposites $(\mathrm{M}=\mathrm{Ag}, \mathrm{Pd}, \mathrm{Au}, \mathrm{Pt})$ and their optical properties, $\mathrm{CO}$ oxidation performance, and antibacterial effect. Nano Res. 2010;3(4):244-255. doi:10.1007/s12274-010-1027-z

34. Usman MS, El Zowalaty ME, Shameli K, et al. Synthesis, characterization, and antimicrobial properties of copper nanoparticles. Int $J$ Nanomedicine. 2013;8:4467. doi:10.2147/IJN.S37465

35. Tran, N., Mir A, Mallik D, et al. Bactericidal effect of iron oxide nanoparticles on Staphylococcus aureus. Int $J$ Nanomedicine. 2010;5:277

36. Han S, Zhang H, Xie Y, et al. Application of cow milk-derived carbon dots/Ag NPs composite as the antibacterial agent. Appl Surf Sci. 2015;328:368-373. doi:10.1016/j.apsusc.2014.12.074

37. Hou YX, Abdullah H, Kuo DH, Leu SJ, Gultom NS, Su CH. A comparison study of $\mathrm{SiO} 2 /$ nano metal oxide composite sphere for antibacterial application. Compos Part B Eng. 2018;133:166-176. doi:10.1016/j.compositesb.2017.09.021

38. Fakhri A, Naji M, Nejad PA. Adsorption and photocatalysis efficiency of magnetite quantum dots anchored tin dioxide nanofibers for removal of mutagenic compound: toxicity evaluation and antibacterial activity. J Photochem Photobiol B. 2017;173:204-209. doi:10.1016/j.jphotobiol.2017.05.041

39. Yehan Y, Zhang K, Yu H, et al. Sensitive detection of sulfide based on the self-assembly of fluorescent silver nanoclusters on the surface of silica nanospheres. Talanta. 2017;174(p):387-393. doi:10.1016/j. talanta.2017.06.027

40. Lijun L, Yu L, Chen X, et al. Synthesis and characterization of binaphthalene-2,2'-diamine-functionalized gold nanoparticles. $J$ Nanopart Res. 2017;19:344-358. doi:10.1007/s11051-017-4040-2

41. Houjuan, Zh., Yu T, Xu H, et al. Fluorescent nanohybrid of gold nanoclusters and quantum dots for visual determination of lead Ions. ACS Appl Mater Interfaces. 2014;6:214-225.
International Journal of Nanomedicine

\section{Publish your work in this journal}

The International Journal of Nanomedicine is an international, peerreviewed journal focusing on the application of nanotechnology in diagnostics, therapeutics, and drug delivery systems throughout the biomedical field. This journal is indexed on PubMed Central,

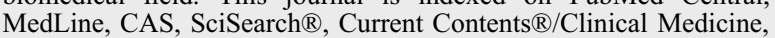

Journal Citation Reports/Science Edition, EMBase, Scopus and the Elsevier Bibliographic databases. The manuscript management system is completely online and includes a very quick and fair peer-review system, which is all easy to use. Visit http://www.dovepress.com/ testimonials.php to read real quotes from published authors. 